\title{
ANALISIS KETERLAMBATAN PENYEDIAAN MATERIAL TERHADAP KETEPATAN WAKTU PEMBANGUNAN
}

\author{
(Analysis of Material Delays in The Timeliness of Development) \\ Amdiya Huqban ${ }^{1}$, Paikun ${ }^{2}$, Cece Suhendi ${ }^{3}$ \\ 1,2,3 Universitas Nusa Putra Sukabumi
}

Korespondensi Penulis: Kp. Pada Asih RT.01/RW.01 Desa Mekarasih Kab. Sukabumi

Email: AmdiyaHq@gmail.com, paikun@nusaputra.ac.id, cece.suhendi@nusaputra.ac.id

Diterima: September 2019; Direvisi (Revised): Desember 2019; Disetujui untuk Dipublikasikan (Accepted): Maret 2020

\begin{abstract}
ABSTRAK
Analisis keterlambatan material terhadap ketepatan waktu pembangunan Keterlambatan proyek sering kali terjadi pada setiap pekerjaan pembangunan. Penyebab tersebut biasa terjadi karena kurangnya penjadwalan proyek secara matang. Oleh sebab itu managemen waktu adalah cara bagaimana untuk mengatur dan meminimalisir terjadinya keterlambatan proyek. Analisa ini di maksudkan untuk membuat penjadwalan ulang proyek dengan adanya keterlambatan material. Analisa ini di batasi hanya mengambil material-material terbesar pada setiap item pekerjaan. Dengan analisa diagram grafik curva s dan diagram batang maka telah teridentifikasi material yang terlambat secara signifikan yaitu hebel, genteng, nok, keramik dan gypsum ratarata mengalami keterlambatan hingga 90\%. Metode yang di pakai untuk meneyelasaikan ketepatan waktu ini, dengan menggunakan metode critichal path metode (CPM) namun dalam metode ini tidak masukan biaya, metode hanya di pakai untuk menghitung waktu/jalur kritis pekerjaan saja. Dalam keterlambatan material yang telah di ketahui, maka dilakukanlah penjadwalan ulang atau Critichal Path Metode (CPM) Rekayasa. Metode ini di lakukan dengan cara mendahulukan item pekerajaan sebelum pasangan dinding hebel dan hasil yang di dapat yaitu waktu pekerjaan tetap 12 minggu dengan ketentuan untuk material struktur beton tidak mengalami keterlambatan yang signifikan.
\end{abstract}

Kata kunci: managemen waktu, keterlambatan material, Critichal Path metode (CPM)

\section{ABSTRACT}

Analysis of material delays in the timeliness of development. Project delays often occur in every construction work. The cause is usually due to lack of careful project scheduling. Therefore time management is a way to manage and minimize project delays analysis is intended to make the project rescheduled due to material delays. This analysis is limited to only taking the largest materials on each work item. With the analysis of the curva s and bar charts it has been identified that the material is significantly late, namely hebel, tile, rooftop, ceramic and gypsum, which on average experiences a delay of up to $90 \%$. method used to solve this timeliness, using the critical path method (CPM) method, but in this method does not enter costs, the method is only used to calculate the time I critical path of the job. In the delay of material that has been known, then rescheduling or Critichal Path Method (CPM) Engineering is carried out. This method is done by prioritizing the workmanship items before the hebel wall pair. And the results obtained are 12 weeks of permanent work with the provisions for concrete structure material not experiencing significant delays.

Keywords: Time management, material delays, critichal Path method (CPM 


\section{PENDAHULUAN}

Dalam setiap pembangunan, perencanaan merupakan hal yang sangat penting sebelum proyek itu mulai dikerjakan. Perencanaan biasanya meliputi progress waktu pembangunan (time schedule), dan pengaturan pengiriman bahan material yang harus di jadwalkan dengan teratur, hal ini termasuk dalam managemen proyek. Managemen proyek juga menjelaskan tentang bagaimana caranya mengatur sumber daya secara efektif dan efisien agar tujuan proyek tercapai secara optimal.

Manajemen proyek adalah semua perencanaan, pelaksanaan, pengendalian, dan koordinasi suatu proyek dari awal (gagasan) hingga berakhirnya proyek untuk menjamin proyek secara tepat waktu, tepat biaya, dan tepat mutu, Ervianto (2002). Managemen proyek adalah suatu cabang khusus dalam managemen. Bidang ini tumbuh dan berkembang karena adanya kebutuhan dalam dunia industri modern untuk mengkoordinasi dan mengendalikan berbagai kegiatan yang kian kompleks, Dennis Lock (1984).

Dalam proses pekerjaan di lapangan biasanya selalu ada masalah yang sering terjadi yaitu terlambatnya pengiriman material sehingga mempengaruhi target waktu pekerjaan dan sering pula terjadi halhal yang di luar perkiraan perencanaan. Suatu proyek tentunya memiliki target atau waktu yang sudah di rencanakan. Beberapa kontraktor memiliki cara ataupun metode tersendiri untuk mengantisipasi terjadinya keterlambatan dalam masalah pengiriman material maupun keterlambatan waktu proses pembangunan itu sendiri. Secara umum metode yang sering di gunakan yaitu CPM (Critical path method). Metode jalur kritis (Critical Path Method-CPM), yakni metode untuk merencanakan dan mengawasi proyek-proyek merupakan sistem yang paling banyak dipergunakan diantara semua sistem lain yang memakai prinsip pembentukan jaringan, Menurut Levin dan Kirkpatrick (1972). Metode ini di pakai pada saat proyek sedang berjalan. CPM (Critical path method) yaitu metode tentang bagaimana cara mengoptimalkan proyek melalui pengurangan waktu dengan mencari jalur kritis pada proyek tersebut. adapun metode lain yaitu PERT (program evaluation and Review Technique), metode ini biasanya di pakai sebelum proyek di mulai atau belum berjalan.

Permasalahan yang sering terjadi dalam proyek konstruksi adalah adanya keterlambatan penyediaan material sehingga dapat mempengaruhi waktu selesainya proyek tersebut. Proyek sering terjadi keterlambatan akibat penyediaan material yang tidak tepat waktu, oleh karena itu, bagaimana cara mengantisipasi agar waktu pelaksanaan tepat sesuau schedule rencana walaupun terjadi keterlambatan penyediaan material. Penulis berhipotesis dengan melakukan rekayasa urutan pekerjaan yang tepat menggunakan metode jalur kritis (Critical path method) pelaksanaan proyek dengan keterlambatan penyediaan material tertentu, tetap dapat diselesaikan tepat berdasarkan schedule rencana, maka dari itu penelitian ini dianggap perlu dan penting.

\section{METODE PENELITIAN}

\section{Lokasi Dan Objek Penelitian}

Penelitian ini dilakukan Proyek Bangunan Fasilitas Farm Ciroyom Purabaya $1 \mathrm{Kp}$. Ciroyom Kec. Purabaya Kab. Sukabumi dan Objek penelitian yang ditinjau adalah Material yang terlambat dikirim juga keterkaitannya terhadap waktu pembangunan bangunan fasilitas ciroyom purabaya 1 Kabupaten Sukabumi.

\section{Kerangka Penelitian}

Analisa ini menjelaskan keterkaitan keterlambatan dalam pengiriman material dan ketepatan waktu pembangunan. Dalam hal ini akan teridentifikasi jenis-jenis material apa saja yang mengalami keterlambatan dalam pengiriman dan setelah di ketahui jenis material apa saja yang terlambtat maka di buatkan sebuah metode untuk mengantisipasi terjadinya keterlambatan proyek Dimana nantinya akan menghasilkan kesimpulan bahwa dengan adanya keterlambatan material, bangunan bisa selesai dengan waktu yang di rencanakan. 
Dalam Analisis Keterlambatan Material Terhadap Ketepatan Waktu Pembangunan ini digunakan data sekunder berupa Time Schedule rencana, Daftar kebutuhan material, jadwal pengiriman barang. Berdasarkan data sekunder tersebut dilakukan analisis yang terjadi dilapangan kemudian dilakukan rekayasa time schedule rekayasa. Metode yang digunakan dalam melakukan analisis time schedule rekayasa yakni metode CPM (Critical path method). Tahapan penelitian ini dijelaskan secara ringkas dalam Gambar 1.

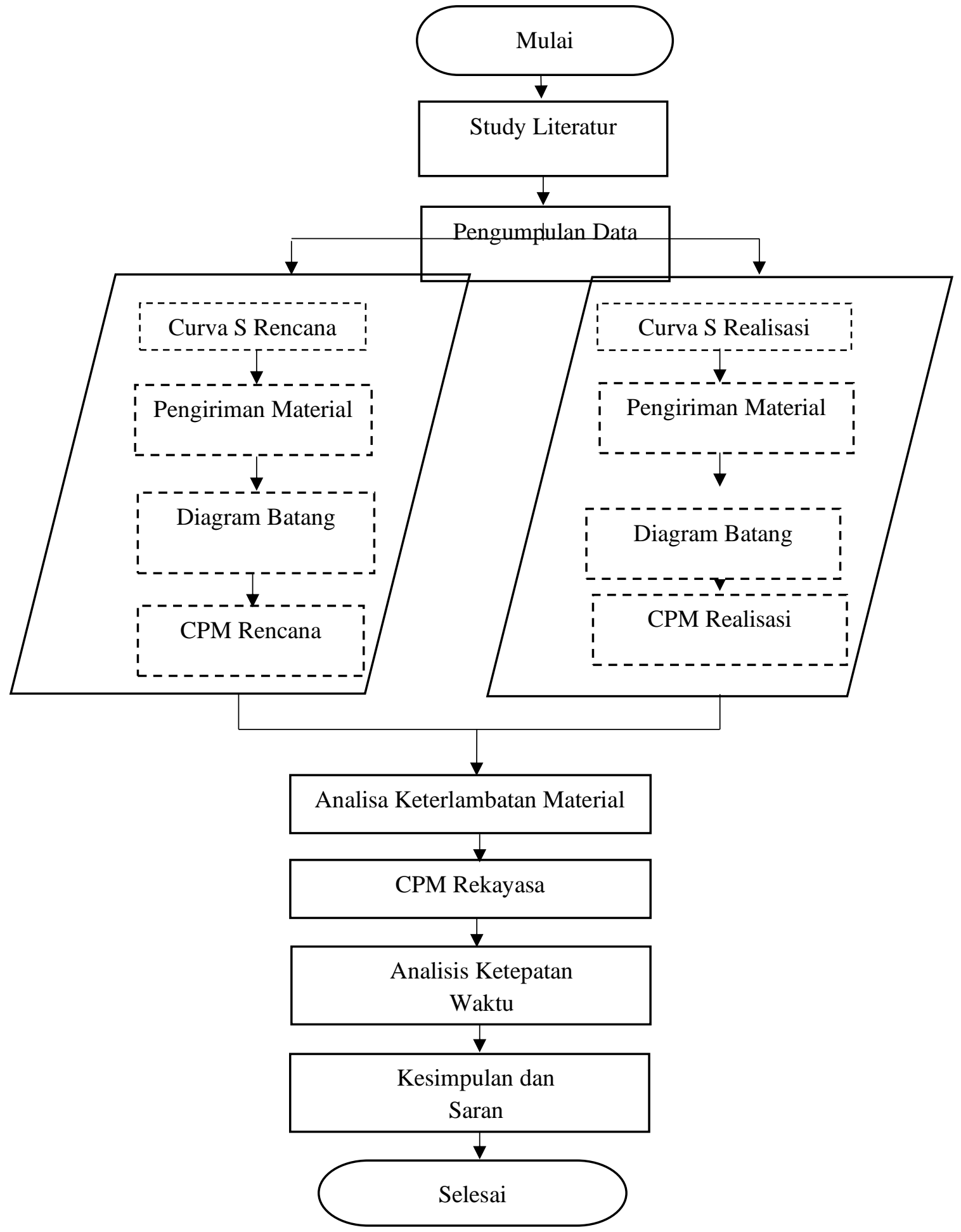

Gambar 1. Alur penelitian 


\section{HASIL PENELITIAN}

\section{Rencana Pelaksanaan}

Penulis telah melakukan penelitian dengan melakukan investigasi untuk mendata proyek pembangunan mess karyawan. Pencatatan meliputi data rencana waktu pelaksanaan, data pengiriman material yang telah dibuat sesuai perencanaan awal, kemudian di bandingkan dengan realisasi pengiriman material serta waktu pelaksanaan proyek dalam pembangunan mess karyawan yang ditargetkan bahwa pelaksanaan proyek akan selesai dalam 12 minggu atau 100 hari kerja. Time schedule rencana seperti dijelaskan pada Gambar 1:

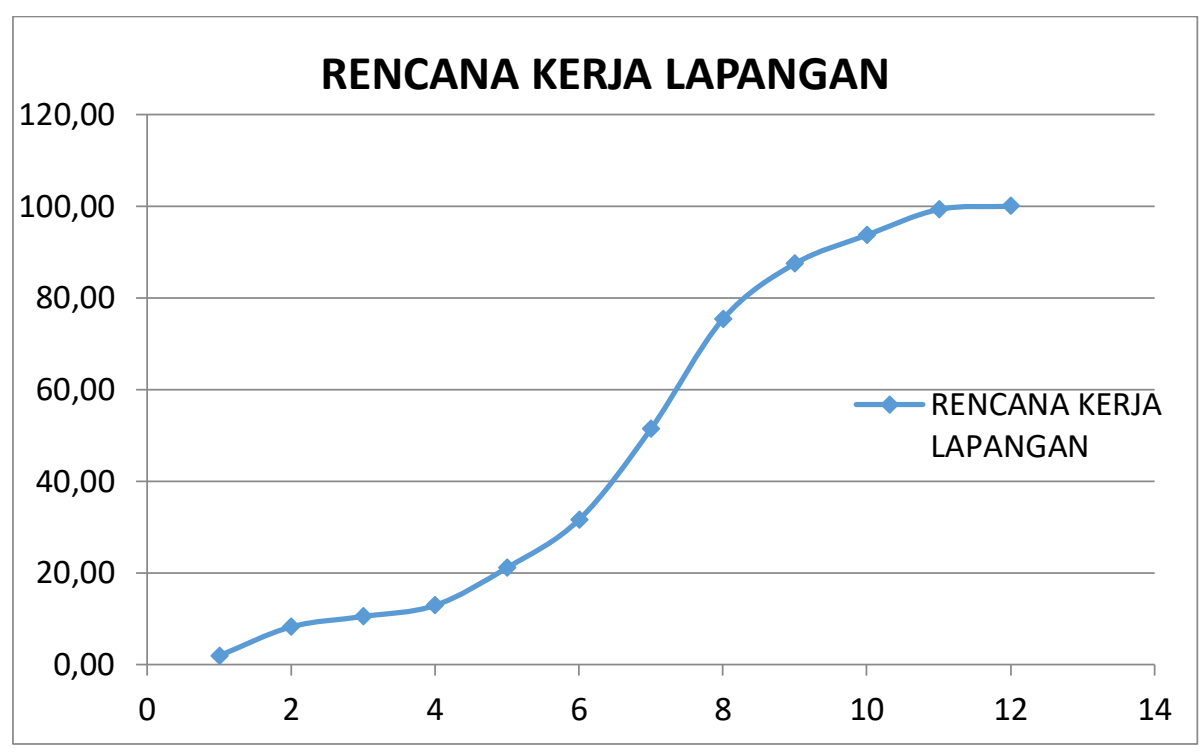

Gambar 2. Rencana schedule pelaksanaan

\section{Realisasi Pelaksaan Proyek}

Berdasarkan investigasi bahwa realsiasi pelaksaan proyek terjadi keterlambatan seperti di tunjukan pada grafik Curva S melalui garis grafik rencan dan grafik realisasi dalam Gambar 2.

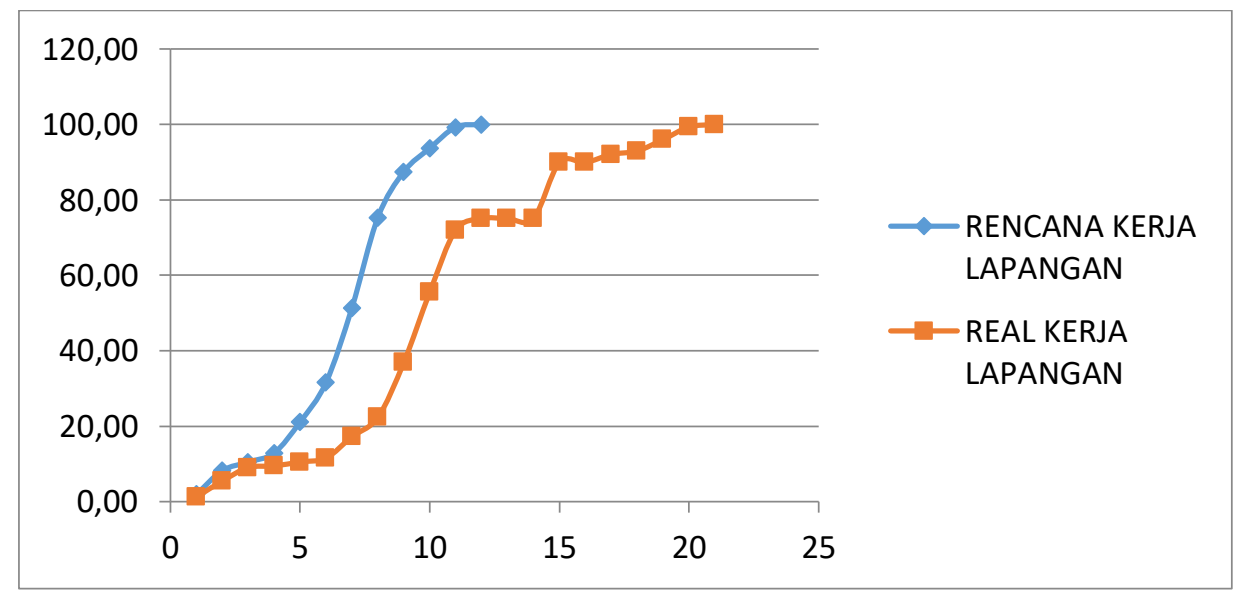

Gambar 3. Grafik schedule rencana dan realisasi

Seperti dijelaskan pada Gambar 2 bahwa pelaksanaan proyek direncanakan 12 minggu, tetapi realisasi pelaksanaan baru dapat diselesaikan dalam waktu 21 minggu, artinya terjadi keterlambatan selama 9 minggu. Keterlambatan proyek tersebut terjadi akibat adanya keterlambatan penyediaan material, hal itu dapat diketahui berdasarkan data rencana pengiriman material dan hasil pendataan realisasi penyediaan material. 
Hasil analisis teridentifikasi bahwa penyediaan material-material yang mengalami keterlambatan seperti dijelaskan pada Tabel 1.

Tabel 1. Jumlah keterlambatan penyediaan material-material berdasarkan kebutuhan dan waktu rencana

\begin{tabular}{llcccc}
\hline No & Deskripsi & $\begin{array}{c}\text { Jumlah } \\
\text { Kebutuhan }\end{array}$ & Jumlah Terkirim & $\begin{array}{c}\text { Jumlah } \\
\text { Terlambat }\end{array}$ & Waktu Keterlambatan \\
\hline 1 & Semen & $756 \mathrm{zak}$ & $529 \mathrm{zak}$ & $227 \mathrm{zak}$ & 7 minggu \\
2 & Split & $18,8 \mathrm{~m} 3$ & $12,8 \mathrm{~m} 3$ & $6 \mathrm{~m} 3$ & 2 minggu \\
3 & Pasir & $170,46 \mathrm{~m} 3$ & $118,46 \mathrm{~m} 3$ & $52 \mathrm{~m} 3$ & 7 minggu \\
4 & Besi & $429 \mathrm{btg}$ & $193 \mathrm{btg}$ & $236 \mathrm{btg}$ & 4 minggu \\
5 & Batu belah & $97,11 \mathrm{~m} 3$ & $48,11 \mathrm{~m} 3$ & $49 \mathrm{~m} 3$ & 1 minggu \\
6 & Hebel & $50,46 \mathrm{~m} 3$ & $0 \mathrm{~m} 3$ & $50,46 \mathrm{~m} 3$ & 3 minggu \\
7 & Genteng & $4501 \mathrm{bh}$ & $0 \mathrm{bh}$ & $4051 \mathrm{bh}$ & 4 minggu \\
8 & Nok & $262 \mathrm{bh}$ & $0 \mathrm{bh}$ & $262 \mathrm{bh}$ & 4 minggu \\
9 & Keramik & $176 \mathrm{dus}$ & $36 \mathrm{dus}$ & $140 \mathrm{dus}$ & 7 minggu \\
10 & Cat & $17 \mathrm{peil}$ & 0 pail & 17 peil & 8 minggu \\
11 & Gypsum & 120 lembar & 0 lembar & 120 lembar & 2 minggu \\
\hline
\end{tabular}

Hasil Analisis seperti ditunjukan pada Tabel 1 bahwa penyediaan material terjadi keterlambatan secara keseluruhan sehingga berpengaruh terhadap keseluruhan pekerjaan proyek terutama akan sangat berpengaruh terhadap waktu penyelesaian proyek.

Setelah mengetahui jenis-jenis material yang mengalami keterlambatan dalam waktu dan jumlah material yang berbeda-beda dan mengakibatkan waktu pelaksanaan proyek tidak sesuai dengan waktu rencana. Dalam perencanaan waktu pelaksanaan proyek harus selesai dalam waktu 12 minggu tetapi akibat adanya keterlambatan penyediaan material, faktanya proyek baru bisa diselesaikan dalam waktu 21 minggu. Berdasarkan data penyediaan material yang mengalami keterlambatan maka dibuatlah rencana pelaksanaan menggunakan metode CPM (critical Path Methode). Metode CPM inilah yang dijadikan acuan dalam pelaksanaan proyek. Metode CPM realisasi seperti dijelaskan pada Tabel 2 dan Gambar 4.

Tabel 2. Critichal Path Metode (CPM) Realisasi

\begin{tabular}{lllcc}
\hline NO & KODE & DESKRIPSI & LANJUTAN & WAKTU \\
\hline 1 & A & Pekerjaan Persiapan & B & 2 \\
2 & B & Pekerjaan Tanah & D, C & 2 \\
3 & C & Pekerjaan Pasangan Pondasi & E, F & 2 \\
4 & D & Pekerjaan Sloof Beton & E & 2 \\
5 & E & Pekerjaan Kolom Beton & H & 2 \\
6 & F & Pekerjaan Ring Balok Beton & G, K & 4 \\
7 & G & Pekerjaan Pasangan Dinding & I & 4 \\
8 & H & Pekerjaan Kontruksi Atap & J, I & 5 \\
9 & I & Pekerjaan Pasangan Plafond & J, M & 2 \\
10 & J & Pekerjaan Kusen Dan Pintu & L & 2 \\
11 & K & Pekerjaan Lantai & M & 2 \\
12 & L & Pekerjaan Cat Dinding & - & 4 \\
13 & M & Pekerjaan Instalasi Listrik & L & 3 \\
14 & N & Pekerjaan Lain Lain & - & - \\
\hline
\end{tabular}




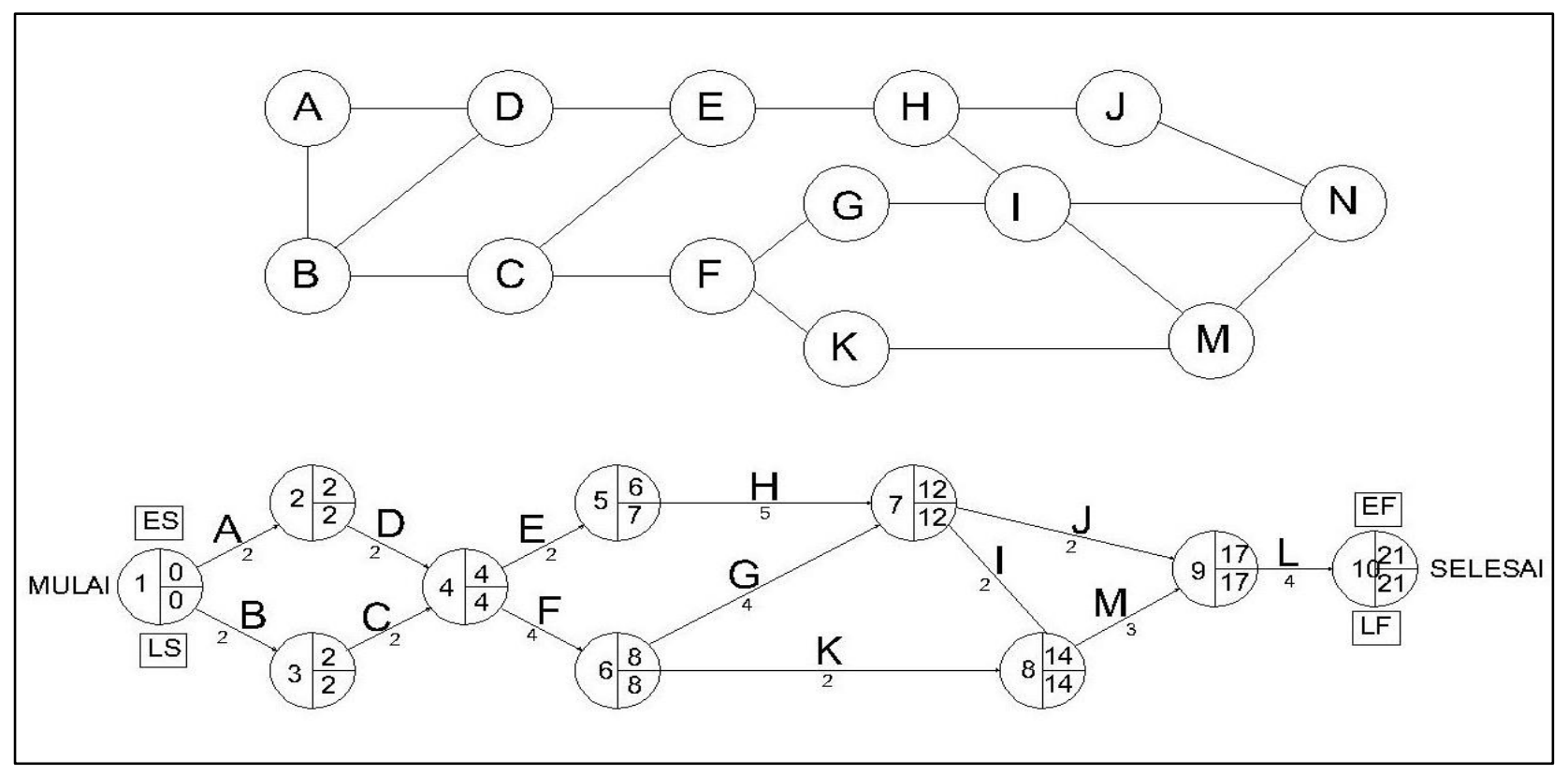

Gambar 4. CPM (Critichal Path Metode) realisai

Hasil analisis metode CPM akibat terlambatnya penyediaan material maka didapatlah waktu penyelesaian proyek selama 21 minggu, dengan jalur kritis yang di dapat yaitu pekerjaan A, B, F, G, I, M, dan L seperti dijelaskan pada Tabel 3 .

Tabel 3. Jalur kritis

\begin{tabular}{clc}
\hline KODE & \multicolumn{1}{c}{ DESKRIPSI } & TOTAL FLOAT \\
\hline A & Pekerjaan Persiapan & 2 Minggu \\
B & Pekerjaan Tanah & 2 Minngu \\
F & Pekerjaan Ring Balok Beton & 4 Minggu \\
G & Pekerjaan Pasangan Dinding & 4 Minggu \\
I & Pekerjaan Pasangan Plafond & 2 Minggu \\
M & Pekerjaan Instalasi Listrik & 3 Minggu \\
L & Pekerjaan Cat Dinding & 4 Minngu \\
\hline
\end{tabular}

Hasil analisis menggunakan metode CPM dengan jalur kritis seperti dijelaskan pada Tabel 3 tidak menyelesaikan masalah, karena proyek seharusnya bisa diselesaikan dengan waktu yang tepat yaitu 12 minggu, oleh karena itu perlu melakukan rekayasa lebih lanjut agar pelaksanaan proyek dapat diselesaikan dalam 12 minggu.

\section{Rekayasa Penyelesaian Proyek}

Dari hasil hasil pengamatan dan hasil analisis terjadinya keterlambatan pengiriman material mengakibatkan keterlambatan penyelesaian proyek. Dengan demikian perlu dilakukan pengaturan ulang penjadwalan pekerjaan dengan menggunakan metode CPM (Critical Path Methode), sehingga meskipun material mengalami keterlambatan tetapi pekerjaan bisa selesai dengan tepat waktu. Setelah teridentifikasi bahwa pekerjaan pasangan dinding bata ringan mengalami keterlambatan selama 3 minggu mundur dari jadwal rencana yang mengakibatkan terjadinya keterlambatan pekerjaan berikutnya, dengan demikian penulis membuat rekayasa ulang pengaturan urutan pelaksanaan pekerjaan menggunakan metode CPM (Critichal Path Metode) untuk mengantisipasi akibat terlambatnya penyediaan material hebel dan material lainnya. Rekayasa CPM agar penyelesaian pekerjaan tepat waktu akibat adanya keterlambatan penyediaan material seperti dijelaskan pada Tabel 4 dan Gambar 5. 
Tabel 5. CPM (Critichal Path Metode) Rekayasa

\begin{tabular}{cclcc}
\hline NO & KODE & DESKRIPSI & LANJUTAN & WAKTU \\
\hline 1 & A & Pekerjaan Persiapan & B, C & 1 \\
2 & B & Pekerjaan Tanah & D & 1 \\
3 & C & Pekerjaan Pasangan Pondasi & F & 1 \\
4 & D & Pekerjaan Sloof Beton & J & 2 \\
5 & E & Pekerjaan Kolom Beton & J & 1 \\
6 & F & Pekerjaan Ring Balok Beton & I, M & 2 \\
7 & G & Pekerjaan Pasangan Dinding & G & 2 \\
8 & H & Pekerjaan Kontruksi Atap & L & 1 \\
9 & I & Pekerjaan Pasangan Plafond & K & 2 \\
10 & J & Pekerjaan Kusen Dan Pintu & L & 2 \\
11 & K & Pekerjaan Lantai & - & 2 \\
12 & L & Pekerjaan Cat Dinding & L & 1 \\
13 & M & Pekerjaan Instalasi Listrik & - & - \\
14 & N & Pekerjaan Lain Lain & . \\
\hline
\end{tabular}

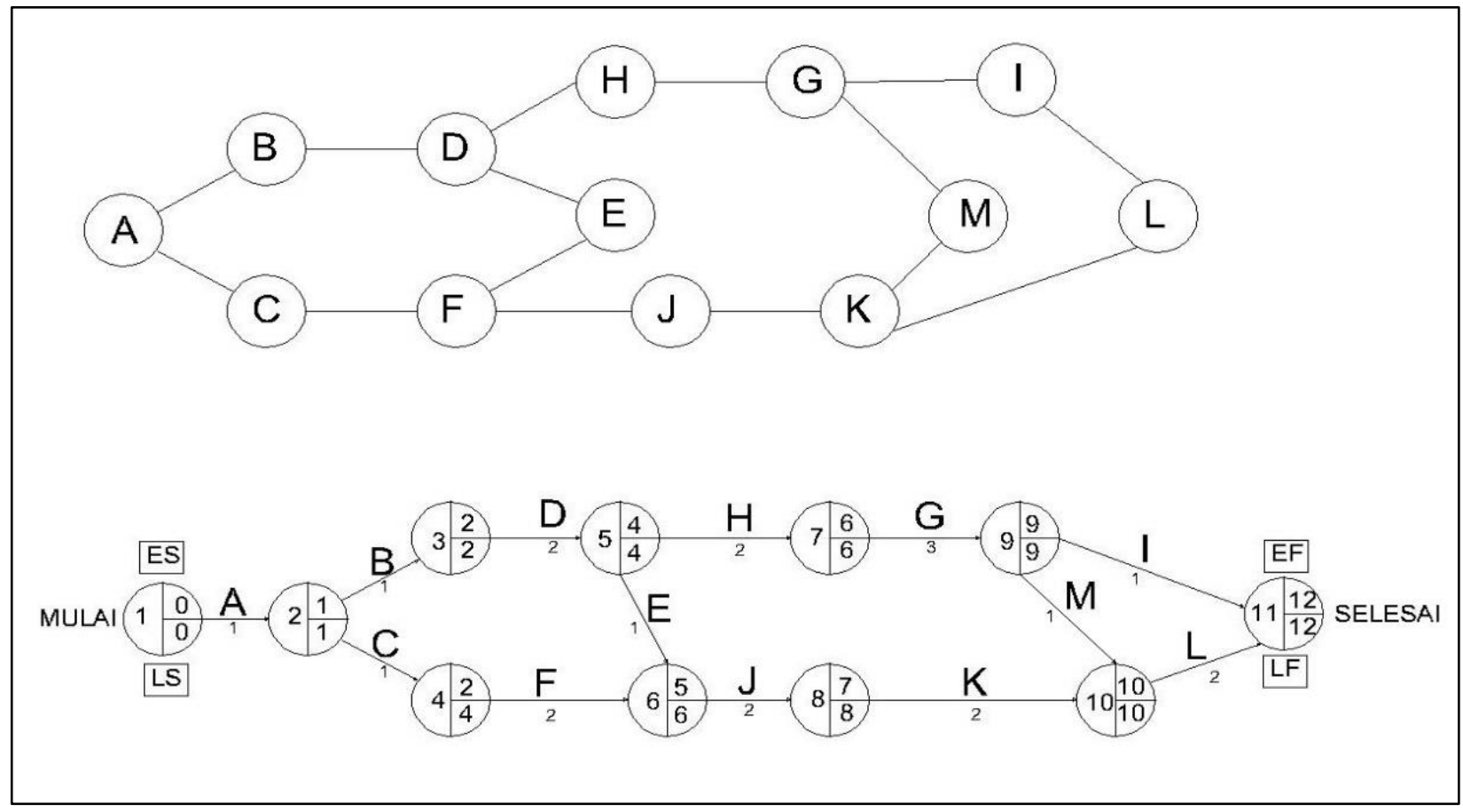

Gambar 5. CPM (Critichal Path Metode) rekayasa

Rekayasa CPM untuk pekerjaan bangunan dengan adanya keterlambatan penyediaan material dapat direkayasa dan didapatkan waktu penyelesaian selama 12 minggu dengan pekerjaan jalur kritis yaitu; pekerjaan persiapan, pekerjaan tanah, pekerjaan sloof beton, pekerjaan konstruksi atap, pekerjaan dinding, pekerjaan instalasi listrik dan pekerjaan cat dinding ( $\mathrm{A}, \mathrm{B}, \mathrm{D}, \mathrm{H}, \mathrm{G}, \mathrm{M}, \mathrm{L})$ dengan waktu pelaksanaan seperti dijelaskan pada jalur kritis Tabel 6. 
Tabel 6. Jalur kritis hasil rekayasa percepatan waktu

\begin{tabular}{clc}
\hline KODE & DESKRIPSI & TOTAL FLOAT \\
\hline A & Pekerjaan Persiapan & 1 Minggu \\
B & Pekerjaan Tanah & 1 Minngu \\
D & Pekerjaan Sloof Beton & 2 Minggu \\
H & Pekerjaan Kontruksi Atap & 2 Minggu \\
G & Pekerjaan Pasangan Dinding & 3 Minggu \\
M & Pekerjaan Instalasi Listrik & 1 Minggu \\
L & Pekerjaan Cat Dinding & 2 Minngu \\
\hline
\end{tabular}

Dalam rekayasa ini pekerjaan persiapan harus dilakukan terlebih dahulu kemudian di lanjutkan dengan pekerjaan tanah dan pondasi selama 1 minggu, dan dilanjut pekerjaan sloof. Pekerjaan kolom dan ring balok harus diselesaikan dalam waktu 2 minggu. Normal pekerjaan sesuai urutan setelah pekerjaan sloof seharusnya langsung pasangan dinding bata ringan (hebel) tetapi karena adanya keterlambatan penyediaan hebel maka pekerjaan ring balok didahulukan kemudian lanjut ke pekerjaan atap. Setelah pekerjaan atap kemudian melaksankan pekerjaan dinding bata ringan dan seterusnya menyesuaikan jadwal. Berdasarkan urutan pekerjaan dan waktu pelaksanaan masing-masing pekerjaan hasil rekayasa CPM, maka pelaksanaan pekerjaan dapat diselesaikan dalam waktu 12 minggu sesuai dengan schedule rencana.

Rekayas CPM yang dihasilkan oleh penulis terdapat perbedaan urutan pekerjaan dengan urutan pekerjaan CPM normal sebelumnya yang mengalami keterlambatan. Perbedaan tersebut sebagai solusi agar penyelesaian proyek tepat waktu akibat terlambatnya penyediaan material. Urutan pekerjaan dengan jalur kritis yang didapatkan dalam rekayasa CPM hasil penelitian ini dapat dipergunakan pada proyek konstruksi lain yang sejenis dengan ketentuan:

1. Mendahulukan pekerjaan ring balok dan pekerjaan atap sebelum pekerjaan dinding hebel.

2. Penyediaan bahan konstruksi structural tidak boleh terlambat

3. Dalam study kasus ini pembangunan menggunakan struktur beton, maka material yang tidak boleh terlambat penyediaannya adalah semen, pasir, koral dan baja tulangan.

Berdasarkan rekayasa metode CPM proyek pembangunan mess karyawan dapat diselesaikan tepat waktu dengan ketentuan material struktur beton tidak boleh terlambat dalam waktu dan persentase yang signifikan.

\section{KESIMPULAN}

Hasil penelitian dapat disimpulkan bahwa penyelesaian proyek konstruksi terjadi keterlambatan selama 9 minggu. Keterlambatan penyelesaian tersebut akibat terlambatnya penyediaan materialmaterial antara lain; semen $30 \%$ selama 7 minggu, split 29\% selama selama 2 minggu, pasir $30 \%$ selama 7 minggu, baja tulangan 55\% selama 4 minggu, batu belah 50\% selama 1 minggu, habel 100\% selama 3 minggu, genteng 100\% selama 4 minggu, bubungan 100\% selama 4 minggu, keramik $80 \%$ selama 7 minggu, cat 100\% selama 8 minggu, gypsum 100\% selama 2 minggu. Faktor utama yang mempengaruhi rangkaian keterlambatan penyediaan material adalah terlambatnya penyediaan habel yang selanjutnya berpengaruh terhadap waktu penyelesaian proyek.

Solusi untuk menyelesaikan proyek tepat waktu akibat terlambatnya penyediaan material hebel adalah rekayasa urutan pekerjaan menggunakan metode CPM (Critical Path Methode) dengan urutan pekerjaan dan waktu pelaksanaan; pekerjaan persiapan 1 minggu, pekerjaan tanah 1 minggu, pekerjaan sloof beton 2 minggu, pekerjaan konstruksi atap 2 minggu, pekerjaan dinding 3 minggu, pekerjaan instalasi listrik 1 minggu dan pekerjaan cat dinding 2 minggu. Menggunakan rekayasa CPM hasil penelitian ini pelaksanaan proyek dapat diselesaikan tepat waktu dengan ketentuan; 1) mendahulukan pekerjaan ring balok dan pekerjaan atap sebelum pekerjaan dinding hebel. 2) penyediaan bahan konstruksi structural seperti semen, pasir, koral dan baja tulangan tidak boleh terlambat. 


\section{DAFTAR PUSTAKA}

Arif Rakhmat Ekanugraha "Evaluasipelaksanaan Proyekdengan Metode Cpm Danpert(Studi Kasus Pembangunan Terminal Binuang Baru Kec. Binuang)”, Fakultas Teknologi Industriuniversitas Islam Indonesiayogyakarta, Tahun 2016.

Ariany Frederika, "Analisis Percepatan Pelaksanaan Dengan Menambah Jam Kerja Optimum Pada Proyek Konstruksi (Studi Kasus: Proyek Pembangunan Super Villa, Peti Tenget-Badung). Universita Udayana, Denpasar Vol. 14, No. 2, Juli 2010.

Eka dannyanti, “Optimalisasi Pelaksanaan Proyek Dengan Metode Pert Dan Cpm”, Fakultas Ekonomi Universitas Diponegoro, Muhammad Rizki Ridho, "Evaluasi Penjadwalan Waktu Dan Biaya Proyek Dengan Metode Pert Dan Cpm (Studi Kasus: Proyek Pembangunan Gedung Kantor Badan Pusat Statistik Kota Medan Di Jl. Gaperta Medan, Sumatera Utara.)", Vol 3 No.1 Tahun 2014.

Ezekiel R. M. Iwawo Jermias Tjakra, Pingkan A. K. Pratasis, "Penerapan Metode Cpm Pada Proyek Konstruksi (Studi Kasus Pembangunan Gedung Baru Kompleks Eben Haezar Manado” Jurnal Sipil Statik Vol.4 No.9 September 2016

Hasolowan Benget Sianipar, Analisis Faktor-faktor peneyebab keterlambatan penyelesaian proyek kontruksi pengaruhnya terhadap biaya, tahun 2002

Idzurnida Ismael "Keterlambatan Proyek Konstruksi Gedung Faktor Penyebab Dan Tindakan Pencegahannya" Jurnal Momentum, Vol 14, No.1, Institut Teknologi Padang, Februari 2013

Jevri Krisanto Lumbanbatu "Analisis Percepatan Waktu Proyek Dengan Tambahan Biaya Yang Optimum”, Kampus USU Medan,

Retno maharesi, "Penjadwalan Proyek Dengan Menggabungkan Metode PERT Dan CPM”, Fakultas Ilmu Komputer, Universitas Gunadarma.

Seng Hansen, Quantity Suveying, Pengantar Managemen biaya dan Kontrak Kontruksi.

Seng Hansen, Buku Managemen Kontrak Kontruksi

Suyatno, “Analisis Faktor Penyebab Keterlambatan Penyelesaian Proyek Gedung” Universitas Diponegoro Semarang, tahun 2010

Wulfram I, Ervianto, Buku Managemen Proyek Kontruksi 